\title{
Oridonin Enhances Phagocytosis of UV-Irradiated Apoptotic U937 Cells
}

\author{
Yan-Qiu Liu, ${ }^{a, b}$ Song You, ${ }^{b}$ Chun-Ling Zhang, ${ }^{a}$ Shin-ichi Tashiro, ${ }^{c}$ Satoshi OnOdera, ${ }^{c}$ and \\ Takashi IKEJIMA *,a \\ ${ }^{a}$ China-Japan Research Institute of Medical and Pharmaceutical Sciences, Shenyang Pharmaceutical University; \\ Shenyang 110016, China: ${ }^{b}$ Laboratory of Natural Product Biotechnology, Shenyang Pharmaceutical University; Shenyang \\ 110016, China: and ${ }^{c}$ Department of Clinical and Biomedical Sciences, Showa Pharmaceutical University; Machida, \\ Tokyo 194-8543, Japan. Received August 2, 2004; accepted November 22, 2004
}

We previously reported that oridonin, a major component isolated from the plant Rabdosia rubescens HemsL, induced apoptosis in human melanoma A375-S2 and cervical cancer HeLa cells. In the present study, oridonin was first evaluated for its effect on phagocytosis of apoptotic cells by macrophages. Preincubation of human histocytic lymphoma U937 cell-derived macrophages with $2.7 \mu_{\mathrm{M}}$ oridonin significantly augmented phagocytosis of UV-irradiated $\left(2.4 \mathrm{~J} / \mathrm{cm}^{2}, 4 \mathrm{~min}\right) \mathrm{U} 937$ cells undergoing apoptosis in a dose- and time-dependent manner. However, less effect on synthetic fluoresbrite microspheres indicated that enhancement of apoptotic U937 cell uptake by oridonin was a selective effect. The oridonin-augmented phagocytosis was attenuated by anti-human TNF $\alpha$ and IL-1 $\beta$ antisera, suggesting that TNF $\alpha$ and IL-1 $\beta$ participate in the phagocytosis by oridonin-treated U937 cell-derived macrophages. In addition, the similar effect of phagocytosis was observed in oridonin-treated human monocyte-derived macrophages at $4 \mathrm{~d}$ maturation. Taken together, oridonin facilitates the phagocytic activity against apoptotic cells through TNF $\alpha$ and IL-1 $\beta$ release, which may be contribute to its antitumor activities.

Key words oridonin; apoptosis; phagocytosis; macrophage; TNF $\alpha$; IL-1 $\beta$

The aerial part of Rabdosia rubescens is known as "Dong Ling Cao" in China. It has been used, in traditional Chinese medicine, for treatment of various diseases. The bioactive components that have been isolated from $R$. rubescens are diterpenoids, including oridonin, ponicidin, rubescensin $\mathrm{C}$, rubescensin D and others. Oridonin (Fig. 1) has various biological effects, such as anti-tumor, anti-bacteria, scavenging active oxygen free radicals and antimutagenetic effects. ${ }^{1-3)}$ We have reported that oridonin had apoptosis-inducing activities in human melanoma A375-S2 and cervical cancer HeLa cells. $^{4,5)}$

Apoptosis is a conserved mode of cell death that is important for embryogenesis, morphogenesis and normal tissue homeostasis. ${ }^{6}$ Rapid recognition and ingestion of apoptotic cells by phagocytes prevent the release of toxic intracellular contents, thereby attenuate inflammation. ${ }^{7-9)}$ The defect in apoptotic cell removal has been implicated as a cause for different types of chronic inflammation and predisposition to cancer, as well as autoimmune disease. ${ }^{10,11)}$ Previous studies have demonstrated that proinflammatory cytokines potentiated phagocytosis of apoptotic neutrophils by human monocyte-derived macrophages. ${ }^{12}$ Serum-derived protein $\mathrm{S}$ enhanced clearance of early apoptotic cells. ${ }^{13)}$ In addition to physical materials, paclitaxel, a natural diterpene with antitumor activity, was also reported to up-regulate phagocytosis capability of murine macrophages by inducing TNF $\alpha$ and IL-1 $\beta$ production. ${ }^{14)}$ Pycnogenol, a potent free radical scanvenger, results in macrophage activation and the secretion of both TNF $\alpha$ and IL- $1 \beta^{15)}$

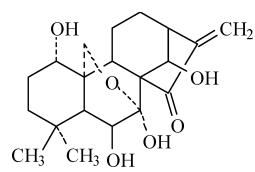

Fig. 1. Chemical Structure of Oridonin
Macrophages are the main phagocytic cells of the innate immune system, responsible for phagocytosis of foreign particles, pathogen and unwanted cells. However, phagocytosis of apoptotic cells was regulated by mechanisms distinct from those modulating phagocytosis of particles or cells coated with Ig and complement. ${ }^{16)}$ Cytokines play an important role in regulating macrophagic phagocytosis of various targets, particularly TNF $\alpha$ and IL- $1 \beta$. These two cytokines exert a wide range of regulatory effect on macrophages. ${ }^{17)}$

To examine phagocytosis, we used differentiated U937 cells as macrophage-like cells induced by $12-O$-tetradecanoylphorbol-13-acetate (TPA). Majority of differentiated U937 cells adhered to the glass bottom and became flat and amoeboid in shape. Moreover, the TPA-treated U937 cells were able to engulf apoptotic U937 cells and microspheres.

In the present study, we for the first time demonstrated that oridonin augmented phagocytosis of UV-irradiated apoptotic U937 cell by macrophage-like cells in a dose- and time-dependent manner. The augmented effect was attenuated by anti-TNF $\alpha$ and anti- IL- $1 \beta$ antibody, indicating that TNF $\alpha$ and IL- $1 \beta$ release was involved in this mechanism. Thus, we examine oridonin's role in regulating immunological processes associated with the clearance of apoptotic cells in addition to inducing tumor cell apoptosis.

\section{MATERIALS AND METHODS}

Reagent Oridonin was obtained from the Kunming Institute of Botany, The Chinese Academy of Sciences (Kunming, China). Paclitaxel, 12-O-tetradecanoylphorbol-13-acetate (TPA), Giemsa staining solution, propidium iodode (PI), Hoechst 33258, acridine orange, and polymyxin B were purchased form Sigma Chemical (St. Louis, MO, U.S.A.). Fluoresbrite polychromatic red microspheres $1.755 \mu \mathrm{m}$ in diameter was purchased from Polysciences (Warrington, PA, U.S.A.). Cell separation solution and fetal calf serum (FCS) 
was purchased from the Dalian Biological Reagent Factory (Dalian, China). Polyclonal rabbit anti-human TNF $\alpha$ antiserum and anti-human IL- $1 \beta$ antiserum were prepared in our laboratory.

Culture of U937 Cells Human histocytic lymphoma (U937 \#CRL-1593.2) cells were obtained from American Type Culture Collection, (Manasas, VA, U.S.A.). The cells were cultured in RPMI 1640 (Gibco, Grand Island, NY, U.S.A.) supplemented with $10 \%$ FCS, $0.03 \%$ L-glutamine (Gibco), penicillin $(100 \mathrm{U} / \mathrm{ml})$, and streptomycin $(100 \mu \mathrm{g} / \mathrm{ml})$ and maintained at $37^{\circ} \mathrm{C}$ with $5 \% \mathrm{CO}_{2}$ in a humidified atmosphere.

The Differentiation of U937 Cells into the Macrophages Was Induced by TPA U937 cells were placed into the individual wells of the 6-well plates at a seeding density of $1 \times 10^{5}$ cells $/ \mathrm{ml}$. TPA was added into each well from a DMSO stock solution to reach the final concentration of $50 \mathrm{ng} / \mathrm{ml}$ (final DMSO concentration was $0.02 \%$, which had no effect on cell differentiation). The cells were incubated at $37^{\circ} \mathrm{C}$ for $15 \mathrm{~h}$ before being used in the experiments. $70 \%$ cells adhered to the plate's bottom by $15 \mathrm{~h}$.

Isolation and Culture of Human Monocyte-Derived Macrophages Human monocytes were separated from whole blood as described previously. ${ }^{18)}$ Blood was obtained from three health adult volunteers. Mononuclear cells were isolated by density centrifugation in cell separation solution. The cells were subsequently cultured as described previously. Briefly, the mononuclear cells were plated at $1 \times 10^{6}$ cells/ well in 6-well plates in RPMI 1640 medium containing 2\% human $\mathrm{AB}$ type serum for $1 \mathrm{~h}$. The monolayers were then gently washed with RPMI 1640 medium and fresh medium was added. These cells were cultured for $4 \mathrm{~d}$ before use for phagocytosis assays.

Observation of Morphological Changes U937 cells in RPMI-1640 medium containing 10\% FCS were seeded into 6-well culture plates. After overnight culture, oridonin was added to the cell culture. For measurement of chromatin condensation, oridonin-treated U937 cells were fixed with Carnoy solution (ethanol: chloroform: acetic acid $6: 3: 1$ ) at room temperature for $10 \mathrm{~min}$, then washed and stained with Giemsa staining solution (Sigma) at room temperature for 10 min. Morphology of U937 cell nuclei was observed under a light microscope (Olympus, Tokyo, Japan).

Flow Cytometric Analysis $2.4 \mathrm{~J} / \mathrm{cm}^{2}, 4 \mathrm{~min}$ UV-irradiated U937 cells $\left(1 \times 10^{6}\right.$ cells $)$ were harvested and washed with PBS. The cell pellets was fixed in $75 \%$ ethanol at $4{ }^{\circ} \mathrm{C}$ overninght. After washing twice with $\mathrm{PBS}$, the cells were stained with $1.0 \mathrm{ml}$ of propidium iodode (PI) solution containing PI $50 \mathrm{mg} / 1$, RNase A $1 \mathrm{~g} / 1$ and $0.1 \%$ Triton X-100 in sodium citrate $3.8 \mathrm{mmol} / 1$, followed by incubation on ice in the dark condition for $30 \mathrm{~min}$. Samples were analyzed by a FACScan flow cytometer (Becton Dickinson, Franklin Lakes, NJ, U.S.A.).

Phagocytosis Assays U937 cells in RPMI 1640 supplemented with $10 \%$ FCS were seeded into 6-well plates $\left(2 \times 10^{5}\right.$ cells/well), in which coverslips $(20 \times 20 \mathrm{~mm})$ were placed, and cultured with $80 \mathrm{~nm}$ TPA at $37^{\circ} \mathrm{C}$ with $5 \% \mathrm{CO}_{2}$ atmosphere for $15 \mathrm{~h}$. The monolayers of U937 cells on coverslips were washed three times with RPMI 1640 medium. After U937 cells treated with UV irradiation $\left(2.4 \mathrm{~J} / \mathrm{cm}^{2}\right.$, $4 \mathrm{~min}$ ) were incubated for $12 \mathrm{~h}$, then the cells $\left(2 \times 10^{6}\right.$ cells/well $)$ were co-cultured with macrophage-like cells on coverslips at $37^{\circ} \mathrm{C}$ for $1.5 \mathrm{~h}$. Floating cells were washed three times with PBS, adhering U937 cells and macrophage-like cells were stained with Giemsa staining solution. Coverslips were examined by light microscopy, and the number of macrophage-like cells that bound and/or engulfed U937 cells was scored. A mininum of 200 cells were counted in random fields in each experimental condition. Results are expressed as the percentage of macrophage-like cells that had taken up U937 cells.

For engulfment assay with fluoresbrite polychromatic red microspheres $1.755 \mu \mathrm{m}$ in diameter, the cells were incubated with the microspheres $\left(2 \times 10^{7} /\right.$ well $)$ in RPMI 1640 medium for $1.5 \mathrm{~h}$. After washing, the cells on the coverslips were fixed with $3.7 \%$ paraformaldehyde at room temperature for $2 \mathrm{~h}$, then stained with Hoechst $33258167 \mu \mathrm{M}$ at $37^{\circ} \mathrm{C}$ for $10 \mathrm{~min}$. The coverlips were observed under a fluorescence microscope (Olympus). The percentage of phagocytosis was determined by same means, as described above.

In addition, phagocytosis was further measured by flow cytometry. UV-irradiated U937 cells were labeled with acridine orange $(10 \mathrm{mg} / \mathrm{l})$ at room temperature for $5 \mathrm{~min}$. Then the labeled cells or red fluoresbrite microspheres were co-incubated with macrophages similarly to the above assay. After washing, the cells on the plate were suspended in PBS, and 10000 cells were analyzed by flow cytometry.

Assay of Endotoxin Activity Purified oridonin used in these experiments were tested for bacterial endotoxin contamination with various doses of polymyxin $\mathrm{B}$, an inhibitor of endotoxins. ${ }^{19)}$ U937 cell-derived macrophages were preincubated with oridonin and polymyxin B at indicated doses, then interacted with apoptotic U937 cells for $1.5 \mathrm{~h}$. Ingesting percentage of U937 cell-derived macrophages were evaluated.

Effects of Antibodies After washing the U937 cell-derived macrophages, polyclonal rabbit anti-human TNF $\alpha$ antiserum (1:10000 dilution) and anti-human IL-1 $\beta$ antiserum ( $1: 1000$ dilution) were added to each well. In preliminary experiments (data not shown), these concentrations of antibodies neutralized TNF $\alpha(10 \mathrm{ng} / \mathrm{ml})$ and IL-1 $\beta(100 \mathrm{ng} / \mathrm{ml})$ completely. The plates were incubated for $12 \mathrm{~h}$, followed by interaction with UV-irradiated apoptotic U937 cells at $37^{\circ} \mathrm{C}$ with $5 \% \mathrm{CO}_{2}$ atmosphere for $1.5 \mathrm{~h}$.

Statistical Analysis All data represent at least three independent experiments and are expressed as mean \pm S.D., unless otherwise indicated. Statistical comparisons were made using Students's $t$-test. $p$-Values of less than 0.05 were considered to represent a statistically significant difference.

\section{RESULTS}

UV Irradiation Induces Apoptotic Cell Death in U937 Cells To assess whether UV-induced U937 cell death was caused by apoptosis, we examined the morphologic changes in cell nuclei. In control group, nuclei of U937 cells were stained homogeneously (Fig. 2a), whereas when U937 cells were incubated for $6 \mathrm{~h}$ after UV irradiation $\left(2.4 \mathrm{~J} / \mathrm{cm}^{2}\right)$, the cells showed marked blebbing of nuclei and apoptotic bodies (Fig. 2b). By 12 h, apoptotic characteristics were more significant (Fig. 2c). The percentage of apoptotic cells was quantitated by flow cytometery. In negative control, the cells at subdipoid peak was not observed (Fig. 2d). The percentage of 

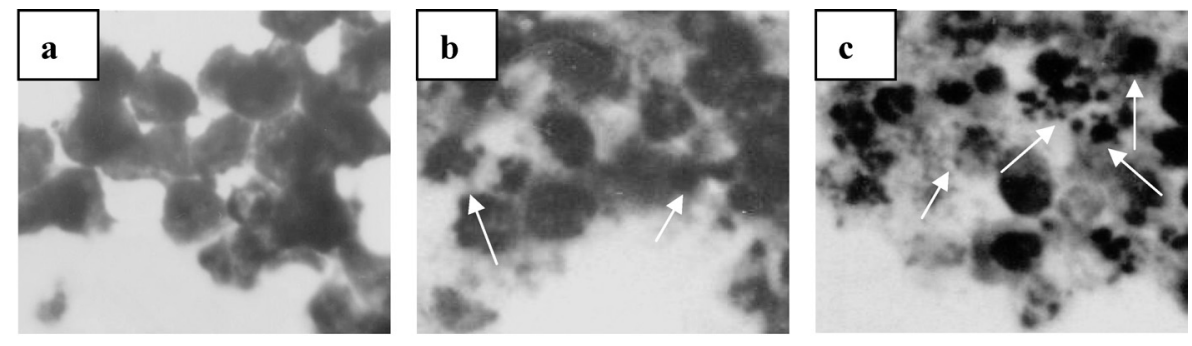

d

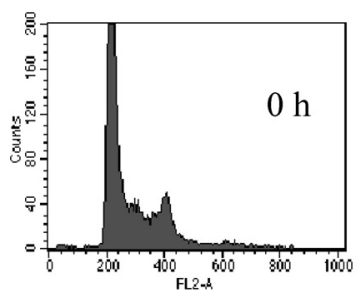

$\mathbf{e}$

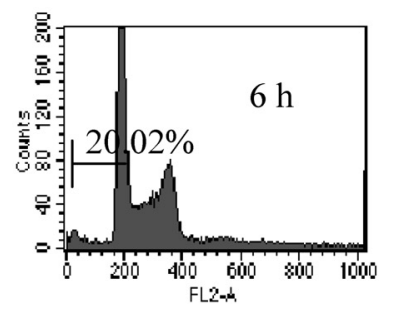

f

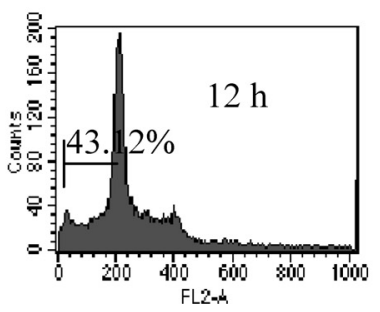

Fig. 2. UV Irradiation Induced Morphologic Changes of U937 Cells

The cells were incubated in 6-well culture plates. Morphological changes of U937 cell nuclei were observed at $0 \mathrm{~h} \mathrm{(a),} 6 \mathrm{~h}$ (b), $12 \mathrm{~h}$ (c) after UV irradiation (2.4 J/cm ${ }^{2}$ ) followed by treatment with Giemsa staining solution at $\times 400$ magnification. Arrows indicate fragmented nuclei. After UV-irradiation, the U937 cells were cultured for $0 \mathrm{~h}$ (d), $6 \mathrm{~h}(\mathrm{e}), 12 \mathrm{~h}$ (f). The cells were washed by PBS and stained with PI followed by flow cytometric analysis.

$\mathbf{a}$

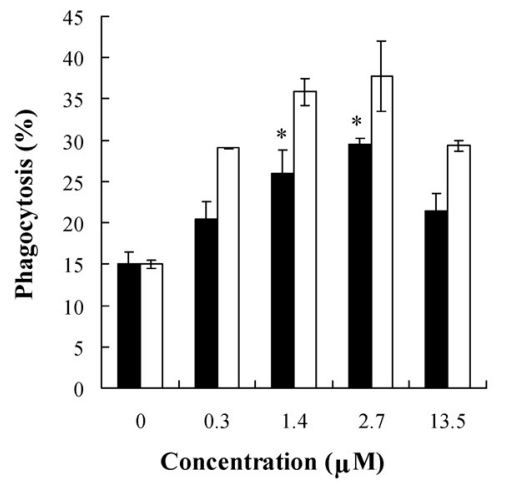

b

Apoptotic U937 cells/ Oridonin
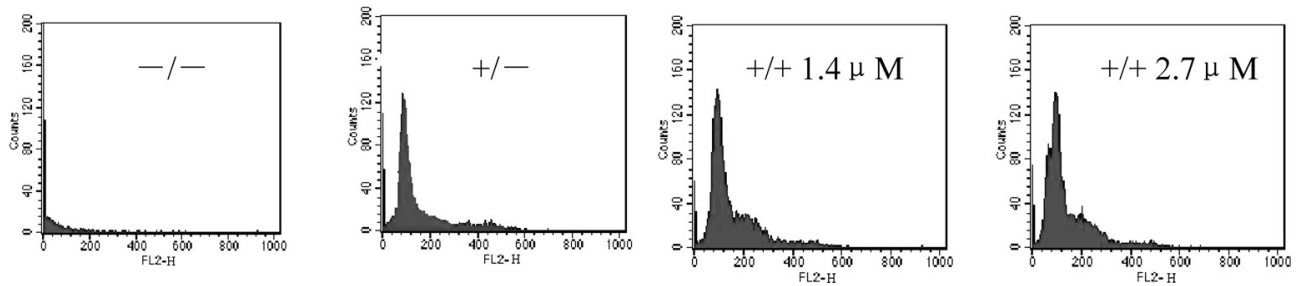

Fig. 3. Dose-Dependent Enhanced Effect of Oridonin on U937 Cell-Derived Macrophage Recognition of Apoptotic U937 Cells

The U937 cell-derived macrophages were preincubated with oridonin (black bars) and paclitaxel (white bars) as a positive control for $12 \mathrm{~h}$ before $1.5 \mathrm{~h}$ interaction with UV-irradiated apoptotic U937 cells. Phagocytosis was then analyzed by a light microscopy (a) or flow cytometry (b). $\overline{\mathrm{x}} \pm \mathrm{s}, n=3, * p<0.05 v s$. medium control group.

apoptotic cells reached $20.02 \%$ by treatment with UV irradiation followed by $6 \mathrm{~h}$ culture (Fig. 2e). After further culture for $12 \mathrm{~h}$, the percentage was approximately two fold higher $(43.12 \%)$ (Fig. 2f). These results demonstrate that certain cause of U937 cell death induced by UV irradiation was apoptosis.

Oridonin Increases the Proportion of U937 Cell-De- rived Macrophages Ingesting Apoptotic U937 Cells To study phagocytosis, U937 cells were induced to undergo apoptosis by treatment with UV irradiation $\left(2.4 \mathrm{~J} / \mathrm{cm}^{2}\right.$, $4 \mathrm{~min}$ ). Phagocytosis assays were carried out by incubating apoptotic U937 cells with TPA-induced U937 cells that were preincubated with oridonin. Oridonin increased the proportion of U937-derived macrophages that engulfed UV-treated 
U937 cells in a dose-dependent manner. With $2.7 \mu \mathrm{M}$ oridonin treatment, the phagocytosis percentage reached from $15.0 \%$ in medium alone to almost $29.5 \%$ (Fig. 3a), consistent with flow cytometric analysis (Fig. 3b). Furthermore, the degree of phagocytosis depended on the time length of U937 cell-derived macrophage culture with $2.7 \mu \mathrm{M}$ oridonin before interaction with apoptotic U937 cells (Fig. 4). The effect was clearly apparent by $6 \mathrm{~h}$ and near maximal by $12 \mathrm{~h}$.

To asess oridonin-augmented phagocytosis, the percentage of U937 cell-derived macrophages that ingested apoptotic U937 cells was determined by a light microscopy. When U937 cell-derived macrophages were cultured with $2.7 \mu \mathrm{M}$ oridonin for $12 \mathrm{~h}$, the increased number of apoptotic cells engulfed by U937 cell-derived macrophages was observed as compared with the untreated control (Figs. 5a, b). After washing the noningested apoptotic cells, the surface of the macrophage-like cells was still adhered to apoptotic cells. Thus, phagocytosis-positive was defined as macrophage-like cells that attached to or engulfed apoptotic cells.

The Oridonin Effect Is Not Induced by Contaminated Endotoxins Enhanced uptake of apoptotic U937 cells triggered by oridonin was not blocked by various doses of polymyxin $\mathrm{B}$, suggesting that oridonin activity was not due to contaminated endotoxins (Table 1). Thus, stimulation of U937 phagocytosis by contaminated endotoxin was excluded.

Oridonin Slightly Increases Uptake of Fluoresbrite Mi-

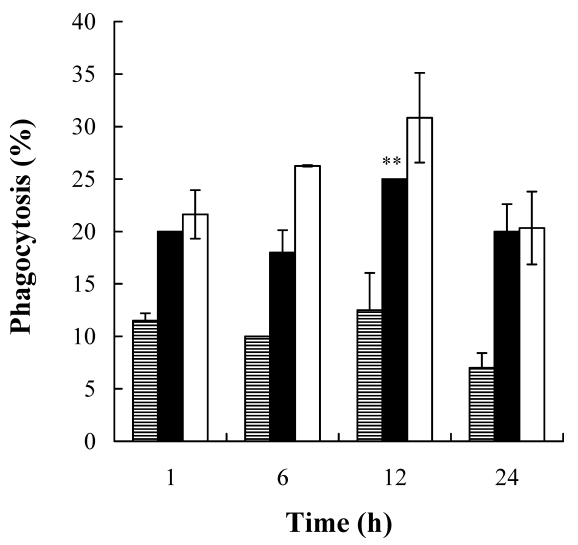

Fig. 4. Time-Dependent Effect of Oridonin on Engulfment of Apoptotic U937 Cells by U937 Cell-Derived Macrophages

Before interacting with apoptotic cells, U937 cell-derived macrophages were incubated with oridonin and paclitaxel at $2.7 \mu \mathrm{m}$ for the indicated time periods. Striated, black and white bars represent medium control, oridonin and paclitaxel, respectively. $\overline{\mathrm{x}} \pm \mathrm{s}, n=3, * * p<0.01 v s$. medium control group.

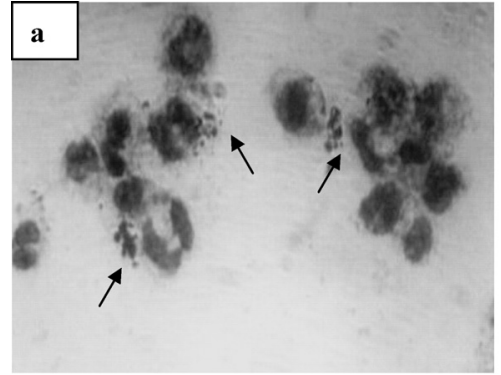

crospheres To determine whether oridonin-stimulated phagocytosis was specific for apoptotic cells, we used fluoresbrite microspheres as nonspecific phagocytic targets. Phagocytosis of fluoresbrite microspheres was assessed by both fluorescence microscopy after Hoechst 33258 staining and flow cytometry. When U937 cell-derived macrophages were treated with various doses of oridonin, the proportion of U937 cells ingesting fluoresbrite microspheres was not markedly increased (Figs. 6a, b, d). Microscopic observation also indicated that the number of U937 cell-derived macrophages containing fluoresbrite microspheres in the presence of oridonin $(2.7 \mu \mathrm{M})$ was comparable to that of negative control (Fig. 6c). Furthermore, oridonin did not increase the recognition of non-apoptotic U937 cells (data not shown). This suggested that enhancement of apoptotic U937 cell uptake by oridonin was a selective effect, rather than nonspecific stimulation of the phagocytic potential of the U937 cell-derived macrophages.

Oridonin-Stimulated U937 Phagocytosis May Require TNF $\alpha$ and IL-1 $\beta$ Production To elucidate what recognition mechanism was recruited by oridonin-stimulated population of U937 cell-derived macrophages ingesting apoptotic U937 cells, we treated the macrophages with TNF $\alpha$ - and IL- $1 \beta$-specific antisera. As shown in Fig. 7, anti-TNF $\alpha$ ( $1: 10000$ dilution) and/or anti-IL-1 $\beta$ (1:1000 dilution) antiserum exerted significant inhibitory effects on oridonin-enhanced phagocytosis, compared with that examined on paclitaxel-enhanced phagocytosis, and reversed the increasing effect of $2.7 \mu \mathrm{M}$ oridonin to the level of untreated control. Our data suggested that oridonin induced the release of biologically active TNF $\alpha$ and IL- $\beta$ by U937 cell-derived macrophages, which might contribute to the phagocytic effect.

Oridonin Acts Not Only on U937 Cell-Derived

Table 1. Effect of Polymyxin B (PB) on Oridonin-Increased Phagocytosis

\begin{tabular}{lc}
\hline \hline Group & Phagocytosis $(\%)$ \\
\hline Control & $14.3 \pm 2.8$ \\
Oridonin (OR) & $25.7 \pm 0.7$ \\
PB $20 \mu \mathrm{g} / \mathrm{ml}$ & $12.7 \pm 3.5$ \\
PB $20 \mu \mathrm{g} / \mathrm{ml}+\mathrm{OR}$ & $22.7 \pm 2.1$ \\
PB $10 \mu \mathrm{g} / \mathrm{ml}$ & $16.3 \pm 2.1$ \\
PB $10 \mu \mathrm{g} / \mathrm{ml}+\mathrm{OR}$ & $22.7 \pm 0.7$ \\
PB $5 \mu \mathrm{g} / \mathrm{ml}$ & $14.0 \pm 1.2$ \\
PB $5 \mu \mathrm{g} / \mathrm{ml}+\mathrm{OR}$ & $23.3 \pm 1.4$ \\
\hline
\end{tabular}

$\overline{\mathrm{x}} \pm \mathrm{s}, n=3$.

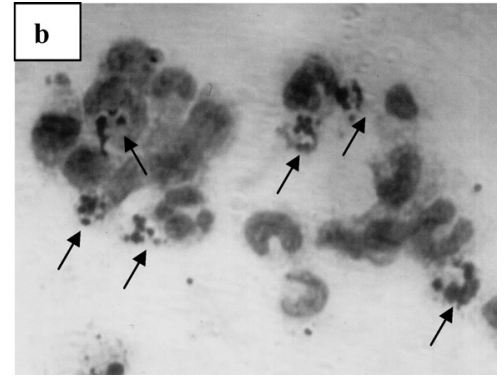

Fig. 5. Light Microphotographs of U937 Cell-Derived Macrophages Co-Incubated with Apoptotic U937 Cells

After preincubation for $12 \mathrm{~h}$ with medium alone (a) or $2.7 \mu \mathrm{M}$ oridonin (b), U937 cell-derived macrophages were incubated for $1.5 \mathrm{~h}$ with apoptotic cells, stained with Giemsa, and observed by light microscopy at $\times 400$ magnification. Arrows indicate apoptotic cells engulfed by U937 cell-derived macrophages. 
a

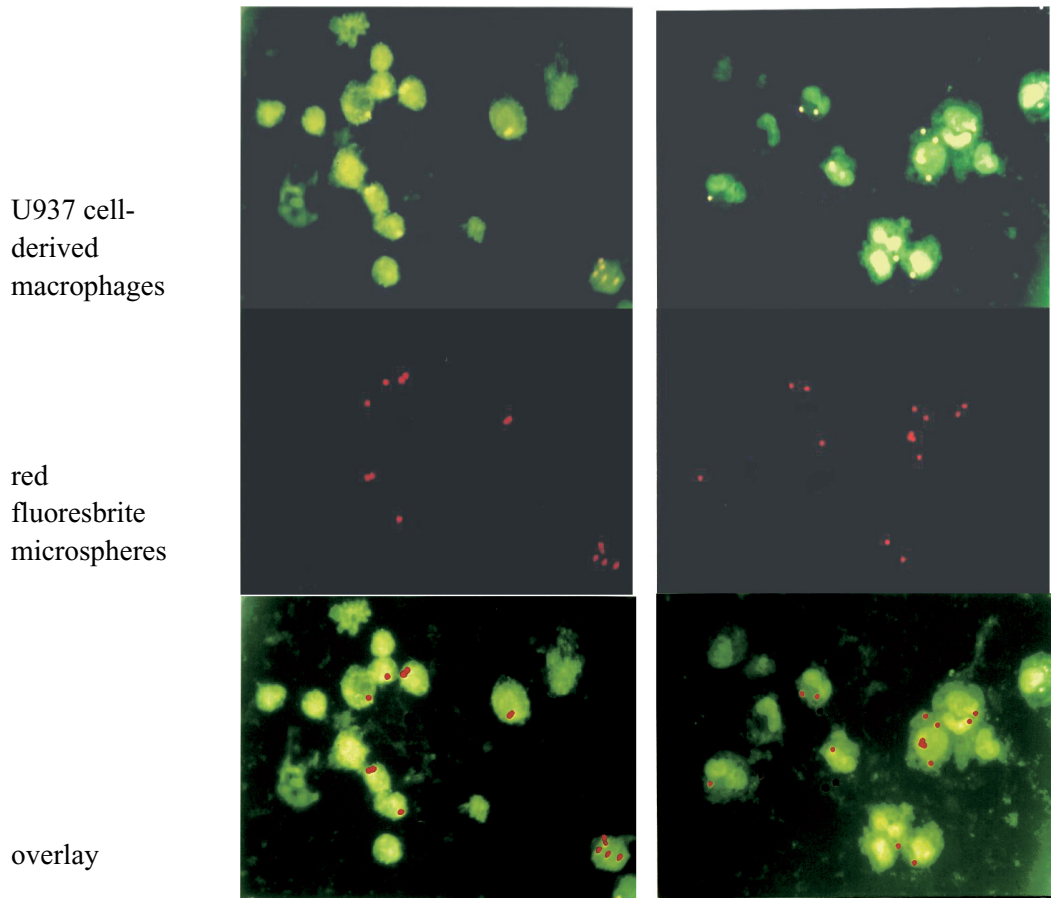

c

\begin{tabular}{lcccccc}
\hline & \multicolumn{5}{c}{ Phagocytosis (\%) } \\
\cline { 2 - 7 } & 0 & 0.3 & 1.4 & 2.7 & 13.5 & $(\mu \mathrm{M})$ \\
\hline Oridonin & $36.0 \pm 1.4$ & $41.5 \pm 2.1$ & $50.0 \pm 1.4^{*}$ & $43.0 \pm 2.8$ & $41.0 \pm 1.4$ & \\
Paclitaxel & $36.0 \pm 1.4$ & $33.0 \pm 0.7$ & $38.8 \pm 1.8$ & $49.9 \pm 3.4$ & $44.6 \pm 8.1$ & \\
\hline
\end{tabular}

d

Red fluoresbrite microspheres / Oridonin
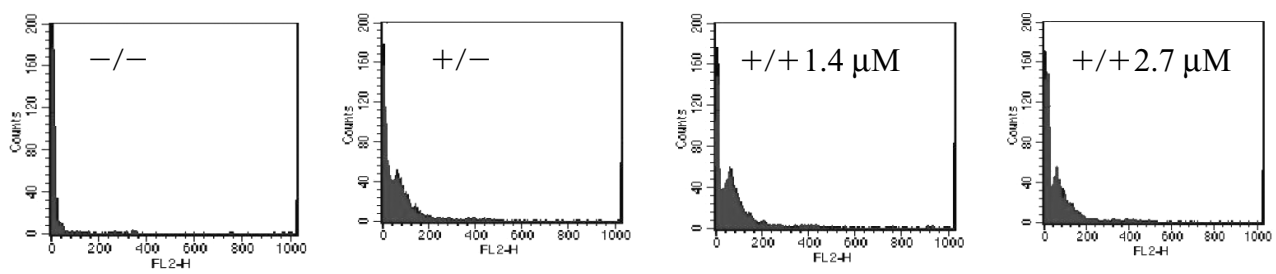

Fig. 6. Oridonin-Stimulated Phagocytic Effect of U937 Cell-Derived Macrophages on Red Fluoresbrite Microspheres

After preincubated for $12 \mathrm{~h}$ with medium alone (a) or $2.7 \mu \mathrm{M}$ oridonin (b), U937 cell-derived macrophages were incubated for $1.5 \mathrm{~h}$ with fluoresbrite microspheres, stained with Hoechst 33258, and observed by fluorescence microscopy at $\times 200$ magnification. Percentage of macrophages carrying fluoresbrite microspheres was quantitated (c). Phagocytosis of fluoresbrite microspheres was further examined using flow cytometry (d). $\overline{\mathrm{x}} \pm \mathrm{s}, n=3, * p<0.05 v s$. untreated group.

Macrophages But Also on Human Monocyte-Derived Macrophages To investigate whether oridonin also act on other macrophages, we further recruited human monocytederived macrophages. As shown in Fig. 8, the phagocytic capability of human monocyte-derived macrophages from three voluteers was increased markedly after treatment of $2.7 \mu \mathrm{M}$ oridonin for $12 \mathrm{~h}$, compared with medium alone. Therefore, oridonin not only increased phagocytosis of U937 cell-derived macrophages but also increased that of human monocyte-derived macrophages.

\section{DISCUSSION}

Cell death by apoptosis is known to delete of unwanted or surplus cells without damaging surrounding tissues. Rapid recognition and ingestion of apoptotic cells avoids leakage of intracellular constituents and induction of an inflammatory response. Thus, efficient removal of tumor cells undergoing apoptosis is of particular importance in the treatment of inflammation. The failure to remove apoptotic cells develops many manifestations associated with autoimmune disease. ${ }^{10)}$ In this study, we have demonstrated that oridonin selectively enhanced phagocytic activities against UV-irradiated apoptotic U937 cells and this phagocytosis was regulated by TNF $\alpha$ and IL- $1 \beta$ secretion.

Based on the observation of morphologic changes in cellular nuclei and flow cytometric analysis, UV-irradiation induced apoptosis in U937 cells. Oridonin effectively enhanced 


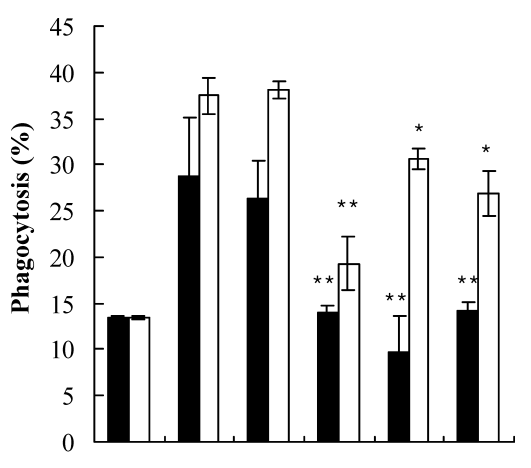

$0.1 \%$ normal rabbit serum

Oridonin/paclitaxel

anti-TNF $\alpha$ antiserum

anti-IL-1 $\beta$ antiserum

Fig. 7. Specific Inhibitiory Effect of Anti-TNF $\alpha$ and Anti-IL-1 $\beta$ Antibodies on Oridonin-Enhanced U937 Phagocytosis of UV-Irradiated Apoptotic U937 Cells

U937 cell-derived macrophages were cultured in the presence of oridonin (black bars) or paclitaxel (white bars) with anti-TNF $\alpha$ antiserum (1:10000 dilution), anti-IL$1 \beta$ antiserum ( $1: 1000$ dilution) or anti-TNF $\alpha$ plus anti-IL-1 $\beta$ antiserum. $\overline{\mathrm{x}} \pm \mathrm{s}, n=3$, $* p<0.05, * * p<0.01 v s$. oridonin/paclitaxel alone group.

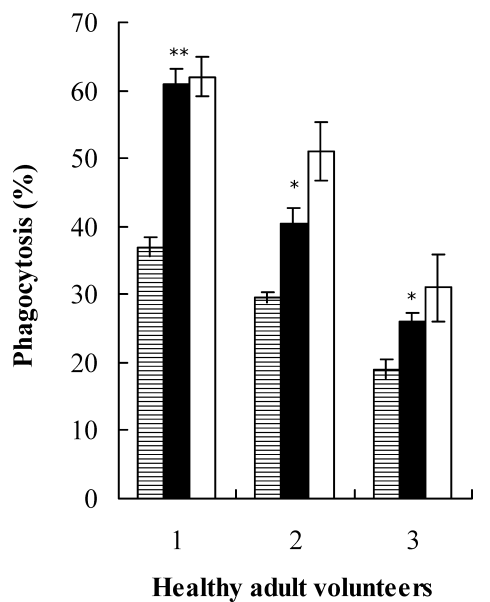

Fig. 8. Effects of Oridonin on Human Monocyte-Derived Macrophages

The monocytes were obtained from three healthy adult volunteers and were cultured on 6-well plates at a density of $5 \times 10^{5}$ cells/well for $4 \mathrm{~d}$. Preincubation of monocyte-derived macrophages with oridonin or paclitaxel for $12 \mathrm{~h}$, was followed by washing and interacting with UV-irradiated apoptotic U937 cells for $1.5 \mathrm{~h}$. Striated, black and white bars represent control, oridonin and paclitaxel, respectively. $\overline{\mathrm{x}} \pm \mathrm{s}, n=3, * p<0.05$, $* * p<0.01$ vs. medium control group.

endocytosis of UV-irradiated apoptotic U937 cells in vitro in a dose- and time-dependent manner. The light microphotographs of macrophages and phagoctosis assay also demonstrated that oridonin is an active material for enhancement of phagocytosis of apoptotic cells by macrophage-like cells.

Previous reports have demonstrated that paclitaxel, a naturally occuring diterpene with antineoplastic agent, induced release of biologically active TNF $\alpha$ and IL- $1 \beta$ by inflammatory murine macrophages, which regulate the ability of

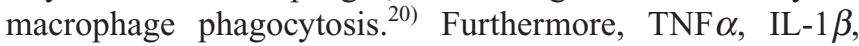
IFN- $\gamma$ and TGF- $\beta 1$ potentiated phagocytosis of neutrophils undergoing apoptosis. ${ }^{1721)}$ Our results showed that oridonin had paclitaxel-like effect on macrophages. At $12 \mathrm{~h}$ after $2.7 \mu \mathrm{M}$ oridonin treatment, population of both U937-derived and human monocyte-derived macrophages that engulfed apoptotic U937 cells was markedly increased. At the same time, proinflammatory cytokines, TNF $\alpha$ and IL- $1 \beta$, began to be released, indicating that oridonin plays an important role in regulation of macrophage function and in the inflammatory responses.

Macrophages constitute a major part of immune system against infection and cancer. They have been of interest in clinical studies since they can act selectively against neoplastic cells. ${ }^{22}$ Cytokine, known to be released from macrophages, exert a wide range regulatory effect on phagocytosis. TNF $\alpha$ and IL- $1 \beta$ were chosen for our investigation because these two cytokines play a critical role in regulating macrophage function. TNF $\alpha$, known for its cytotoxic effect on tumor cells is secreted from activated macrophages. ${ }^{23)} \mathrm{IL}-$ $1 \beta$ activate $\mathrm{T}$ helper cells by acting as a co-stimulator with antigen presenting cells and thus promote cellular immune response. $^{24)}$ In addition, they were able to directly stimulate macrophagic phagocytic activities against apoptotic neutrophils as well as fluorescein-conjugated Escherichia coli paticles, as discussed above. In this study, we used TPAtreated human U937 cells and $4 \mathrm{~d}$ maturated monocyte as macrophage-like cells. They showed significant phagocytic activities in vitro. Incubation of U937-derived macrophages with oridonin resulted in a greater phagocytic activity against apoptotic U937 cells, whereas the augmented effect was reversed to the level of the control group by either anti-TNF $\alpha$ or anti-IL-1 $\beta$ specific serum, suggesting that oridonin stimulates secretion of TNF $\alpha$ and IL-1 $\beta$ in U937-derived macrophages, and that the secreted cytokines, then augmented phagocytic activity in the macrophages. Simutaneously, these two cytokines stimulate the release of each other.

It was reported that macrophagic phagocytosis of apoptotic cells was regulated by mechanism distinct from those of modulating phagocytosis of synthetic particles or cells coated with Ig and complement. ${ }^{25-28)}$ For example, phagocytosis of apoptotic neutrophils by human monocyte-derived macrophages was stimulated by different concentrations of GM-CSF that had no effect on opsonized erthrocytes. ${ }^{12)}$ Our study showed that uptake of fluoresbrite microspheres by U937 cell-derived macrophages was slightly increased by oridonin, in contrast with its potent effect on phagocytosis of apoptotic cells, coincided with previous reports. ${ }^{28)}$

We previously reported that oridonin induced apoptosis in human cervical carcinoma HeLa and human maglignant melanoma A375-S2 cells. The present results show that oridonin appears to have the stimulatory effect on phagocytosis of apoptotic tumor cells, which might contribute to its antitumor activity and stimulate immune functions in cancer patients. Therefore, further research will be required to elucidate the regulatory mechanisms in vivo.

In conclusion, oridonin enhanced phagocytosis of apoptotic U937 cells not only by U937 cell-derived macrophages but also by human monocyte-derived macrophages. However, the effect of oridonin was not strongly exerted on endocytosis of synthetic fluoresbrite microspheres, suggesting that enhancement of apoptotic cell uptake was a selective effect. Oridonin-augmented phagocytosis was blocked by antibody recognizing TNF $\alpha$ or IL- $1 \beta$, indicating that TNF $\alpha$ and IL- $1 \beta$ secretion was involved in the process. 


\section{REFERENCES}

1) Fujita T., Takeda Y., Sun H. D., Minami Y., Marunaka T., Takeda S., Planta Medica, 54, 414-417 (1988).

2) Osawa K., Yasuda H., Maruyama T., Morita H., Takeya K., Itokawa H., Phytochemistry, 36, 1287-1291 (1994).

3) Zhang Y., Wang J., Lou L.G., Zhang T. M., Hou J. W., Xin W. J., Henan Medical Research, 8, 100-104 (1999).

4) Zhang C. L., Wu L. J., Tashiro S., Onodera S., Ikejima T., Acta Pharmacol. Sin., 25, 691-698 (2004).

5) Zhang C. L., Wu L. J., Tashiro S., Onodera S., Ikejima T., J. Asian Nat. Prod. Res., 6, 127-138 (2004).

6) Kerr J. F. R., Winterford C. M., Harmon B. V., Cancer, 73, 2013 2026 (1994).

7) Savill J., Fadok V. A., Nature (London), 407, 784-788 (2000).

8) Cohen J. J., Adv. Immunol., 50, 55-85 (1991).

9) Savill J., Fadok V., Henson P., Haslett C., Immunol. Today, 14, 131136 (1993).

10) Hughes J., Liu Y., Van Damme J., J. Immunol., 158, 4389-4397 (1997).

11) Savill J., Fadok V., Nature (London), 407, 784-788 (2000).

12) Ren Y., Savill J., J. Immunol., 154, 2366-2374 (1995).

13) Anderson H. A., Maylock C. A., Williams J. A., Paweletz C. P., Shu H. J., Shacter E., Nat. Immunol., 4, 87-91 (2002).
14) Bogdan C., Ding A., J. Leukoc. Biol., 52, 119-121 (1992).

15) Shah V., Bayeta E., Lau B. H. S., Pakistan J. Nutr., 1, 196-201 (2002).

16) Sampson L. L., Heuser J., Brown E. J., J. Immunol., 146, 1005-1013 (1991)

17) Arai K., Lee F., Miyajima A., Miyatake S., Arai N., Yokota T., Ann. Rev. Biochem., 59, 783-836 (1990).

18) Doherty D. E., Haslett E. C., Tonnesen M. G., Henson P. M., J. Immunol., 136, 1762-1771 (1987).

19) Park J. M., Greten F. R., Li Z. W., Karin M., Science, 297, 2048-2051 (2002).

20) Mullins D. W., Burger C. J., Elgert K. D., Int. J. Immunolpharmacol., 20, 537-551 (1998).

21) Haslett C., Clin. Sci., 83, 639-648 (1992).

22) Bartholeyns J., Res. Immunol., 144, 288-298 (1993).

23) Currie G. A., Bashan C., J. Exp. Med., 142, 1600-1605 (1975).

24) Gupta S., J. Rheumatol., S76, 189-201 (1988).

25) Becker S., J. Immunol., 132, 1249-1254 (1984).

26) Fleischmann J., Golde D. W., Weisbart R. H., Gasson J. C., Blood, 68 $708-711$ (1986).

27) Te Velde A. A., Klomp J. P. G., Yard B. A., deVries J. E., Figdor C. G., J. Immunol., 140, 1548-1554 (1988).

28) Zuckerman S. H., Surprenant Y. M., Tang J., Blood, 71, 619-624 (1988). 